\title{
NRSF-mediated repression of neuronal genes in developing brain persists in the absence of NRSF-Sin3 interaction
}

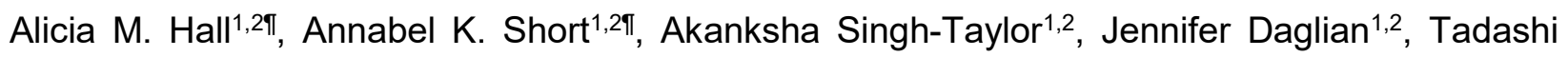
Mishina $^{4}$, William K. Schmidt ${ }^{4}$, Hiroyuki Kouji ${ }^{4,5}$, and Tallie Z. Baram ${ }^{1,2,3 *}$

${ }^{1}$ Department of Anatomy and Neurobiology, University of California, Irvine, USA

${ }^{2}$ Department of Pediatrics, University of California, Irvine, Irvine, California, USA

${ }^{3}$ Department of Neurology, University of California, Irvine, USA

${ }^{4}$ PRISM BioLab Co., Ltd., Nagatsuda-cho, Midori-ku, Yokohama, Japan

${ }^{5}$ Oita University, Faculty of Medicine, 1-1, Idaigaoka, Hasama-machi, Yufu-city, Oita, Japan

${ }^{*}$ Corresponding author e-mail: tallie@uci.edu

I These authors contributed equally to this work.

\begin{abstract}
Repression of target genes by the transcriptional repressor neuronal restrictive silencing factor (NRSF)/repressor element 1 silencing transcription factor (REST) contributes to enduring plasticity in the developing brain. However, the cofactor(s) interacting with NRSF to enable target gene repressor are not well understood, and may vary among neuronal populations and brain regions as well as with different contexts. Here we employed the novel designer drug mS-11 to block the interactions of the cofactor Sin3 with NRSF. We tested if NRSF-Sin3 interaction is required for repression of NRSF target genes in developing hypothalamus after activitydependent modulation of NRSF function. In the hypothalamus in vitro, blocking glutamatergic neurotransmission robustly increased NRSF binding to the target gene Crh, resulting in its repression. Blocking the binding of NRSF to the chromatin with decoy NRSEoligodeoxynucleotides abrogated this repression. In contrast, mS-11 at several concentrations did not impede Crh repression. NRSF-mediated repression may underlie disease processes such as the onset of epilepsy. Therefore, identifying small-molecule antagonists of NRSF is crucial for the development of disease-preventing or modifying interventions.
\end{abstract}

\section{Key words:}

REST, NRSF, drug screen, epigenetics, hypothalamus, $\mathrm{CRH}$, small molecule, oligodeoxynucleotides, neuronal plasticity, neurodevelopmental disease, epilepsy 


\section{Introduction}

The transcriptional repressor neuronal restrictive silencing factor (NRSF or REST) is emerging as an important mediator of neuronal plasticity (1-3). NRSF expression was originally described in non-neuronal tissues where it suppresses neuron-specific genes (4-6), indicating that many neuronal genes must carry NRSF-response elements (NRSE/RE1) and are repressed by augmented NRSF levels or activity $(3,6)$. A second important role for NRSF was established by showing that transition of neuronal precursors to mature neurons requires dissociation of NRSF from the chromatin of neuronal genes (7). More recently, NRSF expression in mature neurons has been described, where the factor may be crucial for normal function (8-10). In differentiated neurons, NRSF is especially crucial to those still developing (11), where expression of NRSFregulated genes contributes to several aspects of maturation, including development of excitatory synapses $(1,2,12,13)$. This is important because many neuropsychiatric disorders seem to originate during the developmental epoch (infancy and early childhood) when neurons are involved in the creation of synaptic contacts and their refinement and pruning to mature circuits $(12,14-17)$.

Indeed, recent evidence suggests that blocking the binding of the transcription factor NRSF to the chromatin in rodent models, ameliorates the development of epileptic seizures, and prevents the development of memory problems, which are seen after insults in humans (18-20). In experimental models, NRSF function was blocked using the administration of decoy oligodeoxynucleotide (ODNs) directly into the brain. However, whereas blocking NRSF holds great promise to modulate epileptogenesis in humans, the administration of ODNs is not clinically practical. These facts provide great impetus for the identification and/or synthesis of smallmolecule 'designer drugs' to block NRSF actions.

NRSF exerts its repressive effects on gene expression by interacting with RE1/NRSE sites and recruiting corepressors including $\operatorname{Sin} 3 A, B$ (Sin3) (7,21-23) G9a and/or CoREST (24-26). These proteins then engage additional transcriptional regulators and cofactors including the G9a histone methyltransferase (27), the histone deacetylases 1 and 2, and the H3 lysine 4 demethylase LSD1 (28), as well as others (29). The interacting cofactors engage distinct domains of the NRSF molecule (Fig 1). Our initial work suggested that cofactors targeting the N-terminus of NRSF might contribute importantly to the actions of the repressor in the postnatal developing brain $(18,30)$. Therefore, we tested the potential role of Sin3, an NRSF-N-terminus interacting cofactor (21), in contributing to NRSF-mediated gene repression in the developing brain. We capitalized on the well-established function of NRSF in the repression of one of its target genes, corticotropin releasing factor, encoded by Crh $(31,32)$ in the hypothalamus. Thus, we employed an in vitro hypothalamic slice-culture system that maintains the integrity of hypothalamic three-dimensional structure yet provides a controllable system. We tested if blocking NRSF-Sin3 interaction, using the small molecule $\mathrm{mS}-11$, prevents the repression of $\mathrm{CRH}$ expression that is observed upon reduction of glutamatergic neurotransmission. In addition, we compared the efficacy of mS-11 to that of an NRSE-ODN that directly interferes with binding of NRSF to the chromatin. 


\section{Materials and Methods}

\section{Drug development}

Computer-driven 3D methodologies were used to design a molecule that mimics the NRSF Nterminus moiety that interacts with the mammalian Sin3B-PAH1 domain. An improved compound called mS-11 was identified. Further details of the compound and its synthesis and testing are provided in Ueda et al., 2017. Because the homology between $\operatorname{Sin} 3 \mathrm{~A}$ and $\operatorname{Sin} 3 \mathrm{~B}$ is quite high in the PAH1 domain, $\mathrm{mS}-11$ is expected to interfere with NRSF binding to Sin3A as well.

\section{In vitro system for NRSF-mediated gene repression}

Organotypic hypothalamic slice cultures were generated from rats as described previously (8). Animals were handled according to $\mathrm{NIH}$ guidelines for care and use of laboratory animals and in accordance with protocol approval from the University of California-Irvine Institutional Animal Care and Use Committee. Subjects were progeny of timed-pregnant Sprague-Dawley rats. Rats were housed under a 12-hour light-dark cycle in humidity and temperature controlled rooms, with ad libitum access to food and drinking water. Parturition was checked daily, and the day of birth was considered postnatal day $(P)$. To generate of hypothalamic explant cultures, pups were sacrificed on P6-7.

Cultures were prepared using a stationary hypothalamic slice culture protocol as previously described (8). Rat pups were decapitated on P6-P7 (weight range 13-17g) (day in vitro (DIV) 0), brains were removed, and hypothalamic blocks were dissected and cut into $350 \mu \mathrm{m}$ coronal sections on Mcllwain tissue chopper in ice cold prep media (MEM (Thermo Fisher Scientific, Waltham, MA)), L-Glutamine (Thermo Fisher Scientific, Waltham, MA), HEPES Buffer (Thermo Fisher Scientific, Waltham, MA), glucose, and cell culture grade water (GE Healthcare, Little Chalfont, UK) in a laminar flow hood. Sections containing the PVN were then maintained on 0.4 $\mu \mathrm{m}, 30 \mathrm{~mm}$ diameter cell culture inserts (Merck Millipore, Darmstadt, Germany) in six well plates with culture media (Minimum Essential Medium, Hank's balanced salt solution, heat-inactivated horse serum, HEPES, glucose, glutamine, ascorbic acid, insulin, $\mathrm{NaHCO}_{3}$, and cell culture grade water). Explants were maintained for 8 days at $37^{\circ} \mathrm{C}$ in $5 \% \mathrm{CO}_{2}$ enriched air in an incubator, with the media refreshed every 48 hours (h). Explants were kept in serum-containing medium from DIV 0 to DIV 6, which also contained antibiotics (penicillin and streptomycin (Thermo Fisher Scientific, Waltham, MA) until DIV 4. On DIV 6 cultures were transferred to serum free media (Minimum Essential Media, HEPES, glucose, glutamine, ascorbic acid, insulin, $\mathrm{NaHCO}$, cell culture grade water), and treated with either sterile nuclease-free tissue-culture grade water (vehicle), or $50 \mu \mathrm{M}$ MK-801 (Sigma-Aldrich, St. Louis, MO) and $50 \mu \mathrm{M}$ CNQX (Sigma-Aldrich, St. Louis, MO). Media containing either vehicle or glutamate receptor antagonists (GluRs) were refreshed every $12 \mathrm{~h}$ for $52 \mathrm{~h}$. After $52 \mathrm{~h}$, cultures were then harvested on dry ice, and stored at $80^{\circ} \mathrm{C}$ until further processing.

\section{Blocking of NRSF function using NRSE-ODNs}

For oligodeoxynucleotide (ODN) treatment, previously described phosphothiolated ODNs consisting of either a control, randomly ordered sequence (scrambled; SCR) or a sequence coding for NRSF binding site (NRSE), were used $(3,18)$. NRSE-ODN sequence: 5'GGAGCTGTCCACAGTTCTGAA-3' and scrambled ODN sequence: 5'AGGTCGTACGTTAATCGTCGC-3' (Sigma). Slices were maintained as described above, transferred to serum free medium on DIV 6, and exposed to one of the following treatments: [Veh + NO ODN], [Veh + SCR], [Veh + NRSE], [CNQX/MK-801+NO ODN], [CNQX/MK-801 + SCR], or 
$[\mathrm{CNQX/MK-801}+\mathrm{NRSE}]$. Dose-response analysis determined $10 \mathrm{nM}$ as the optimal ODN concentration. The ODNs were used only for the first $12 \mathrm{~h}$ of treatment. Media containing either vehicle or antagonists were refreshed every $12 \mathrm{~h}$ for $52 \mathrm{~h}$. Cultures were then harvested and stored as described above. We have previously shown that the ODNs enter neuronal cytoplasm and nuclei $(8,20)$.

\section{Blocking of Sin3-NRSF interaction using mS-11}

The protocol for using mS-11 followed the one described above. Briefly, hypothalamic explants were kept in culture from DIV 0 to DIV 6 . On DIV 6 cultures were treated with either sterile nuclease-free tissue-culture grade water (vehicle), or $50 \mu \mathrm{M} M K-801$ and CNQX to block ionotropic glutamate receptors. Media containing either vehicle or glutamate receptor (GluR) antagonists were refreshed every $12 \mathrm{~h}$ for $52 \mathrm{~h}$. The experimental groups included: [Veh + diluent], [Veh + mS-11], [CNQX/MK-801 + diluent] or [CNQX/MK-801 + mS-11]. Two concentrations of $\mathrm{mS}-11$ were used, and $\mathrm{mS}-11$ was diluted in $0.1 \%$ DMSO and applied directly to the medium for final concentrations of $10 \mu \mathrm{M}$ or $70 \mu \mathrm{M}$. The latter aimed to approximate concentrations achieved upon in vivo administration of the drug, which was given at $30 \mathrm{mg} / \mathrm{kg}$ (PRISM Co. Material, unpublished). Media containing either vehicle, antagonists, mS-11 or antagonists and mS-11, were refreshed every $12 \mathrm{~h}$ for $52 \mathrm{~h}$. Cultures were then harvested and stored as described above.

\section{RNA extraction, reverse transcription, and qRT-PCR}

Samples were thawed on ice, and RNA was isolated using RNeasy Mini Kit (Qiagen, Valencia, CA) as per manufacturer's protocol. RNA was quantified, and purity was analyzed using NanoDrop (Thermo Fisher Scientific, Waltham, MA). It was immediately converted to cDNA with random hexamers using first strand cDNA synthesis kit (Roche, Basel, Switzerland) following manufacturer's protocol. qRT-PCR was performed using SYBR Green chemistry (Roche, Basel, Switzerland) on a Lightcycler 96 (Roche, Basel, Switzerland) with primers for specific transcripts. Gapdh or $\beta$-Actin served as the internal control ('housekeeping gene'), and relative quantification of mRNA expression was accomplished using the cycle threshold method $\left(2^{\wedge}-\Delta \Delta \mathrm{Ct}\right)$. Minusreverse transcription and non-template controls were routinely used to eliminate the possibility of genomic contamination or false positive analyses. Primer sequences used for qRT-PCR have been published (8).

\section{Statistical considerations and analyses}

All analyses were conducted without knowledge of treatment group. Analysis of variance and Tukey's multiple comparison post-hoc tests were employed as required using GraphPad PRISM software. 


\section{Results}

NRSF mediates the repression of its target gene, $\mathrm{Crh}$, that is provoked by reduction of glutamatergic neurotransmission

In accord with our prior observations (Korosi et al., 2010; A Singh-Taylor et al., 2017), blocking of excitatory neurotransmission using a cocktail of glutamate receptor (GluR) antagonists (CNQX/MK-801) to $\mathrm{CRH}$-expressing cells in hypothalamic cultures reduced Crh mRNA levels by around $50 \%$ (Fig 2). Interfering with the binding of NRSF to its recognition site on the chromatin using NRSE-ODN decoys (Fig 2A) abrogated this repression of the Crh gene (Fig 2B; Significant interaction on two-way ANOVA; $F_{[2,77]}=7.09$, $p<0.01$; post hoc, $\left.{ }^{*} p<0.05\right)$. This was specific to NRSF, because a random-sequence (SCR)-ODN had negligible effect on the suppression of $\mathrm{Crh}$ expression (Figs 2B).

These finding indicated that Crh mRNA repression in developing hypothalamus by blocking ionotropic glutamate receptors is a robust and reliable system, which recapitulates an in vivo repression by early-life experience $(33,35-37)$. Further, the Crh mRNA repression requires the function of NRSF. We then set out to determine if the interaction of NRSF with the cofactor Sin3 is required for NRSF to repress $\mathrm{Crh}$. This was accomplished by the use of a compound designed to mimic the Sin3B-PAH1-interacting domain of NRSF (38).

\section{mS-11 does not prevent repression of Crh mRNA after ionotropic glutamate receptor blockade}

To examine if Sin3-NRSF interaction is required for the NRSF-mediated repression of Crh mRNA expression in hypothalamus, we incubated hypothalamic explants with two distinct concentration of the mS-11. As is shown in Fig 3, blocking ionotropic glutamate receptors (using CNQX/MK801) robustly repressed CRH mRNA levels. However, this reduction was not influenced by either $10 \mu \mathrm{M}$ (Fig 3A; Significant main effect of GluR antagonists on two-way ANOVA; $F_{[1,12]}=104.5$, $\mathrm{p}<0.001$ ) or $70 \mu \mathrm{M}$ concentrations of $\mathrm{mS}-11$ (Fig 3B; Significant main effect of GluR antagonist on two-way ANOVA; $\left.F_{[1,12]}=15.93, p<0.01\right)$. The higher concentration is well in line with those employed in vivo (38) and in vitro (PRISM Co. Datasheet, $\mathrm{H}$. Kouji, personal communication). In addition, this concentration resulted in apparent toxicity within the cultures, suggesting that it is limiting.

\section{Discussion}

The principal findings in these series of experiments are (1) NRSF binding to cognate recognition sites within the Crh gene contributes critically to NRSF-mediated repression of this target gene in the developing brain; (2) interaction and recruitment of the $\mathrm{N}$-terminus cofactor Sin3 may not be necessary for this repression.

The mechanisms by which experience, environment and activity early-in life lead to persistent, epigenetic changes in gene expression are a topic of major importance $(32,39,40)$. These epigenetic changes may be critical components of neurodevelopmental as well as later-onset brain disorders $(15,17,41,42)$. Networks of transcription factors and cofactors, together with chromatin modulations $(7,24,25,43)$ and numerous other signals mediate the enduring effects of early-life experiences on gene expression in specific neurons $(30,44)$.

Whereas the involvement of NRSF in neuronal plasticity in developing hippocampus $(20,26,45)$ and hypothalamus (8) is established, the molecular machinery engaged by NRSF is not well understood. NRSF recruits a number of molecules and molecular complexes $(22,25,26,29)$, which 
may contribute to initiation of gene repression. For some genes, the level of expression is adjusted further in neurons by CoREST/MeCP2 repressor complexes as well as others that remain bound to a site of methylated DNA distinct from the RE1 site $(7,18)$. Therefore, direct interference with NRSF-binding may not be specific to a given gene set.

To determine therapeutic approaches of NRSF interference that are applicable to clinical use, it is important to determine the mechanisms by which NRSF interacts with cofactors to repress gene expression. Current manipulations of NRSF-binding in animal studies involve administration of genetic material directly to the brain $(3,18)$, however these are not appropriate for clinical translation. $\operatorname{Sin} 3$ is an attractive candidate for interfering with NRSF function. The N-terminal repressor domain of NRSF recruits this corepressor (also called $\mathrm{mSin}$ ) which comes in two isoforms (A and B). Sin3A is recruited by NRSF in hippocampus (22). In addition, Sin3 is involved in the interaction of NRSF and the huntingtin gene product (46). This co-repressor consists of four paired amphipathic helix (PAH) domains called PAH1-PAH4. The structure of the PAH1 domain of $\mathrm{mSin} 3 \mathrm{~B}$ in complex with the N-terminal repressor of NRSF has been resolved, providing the template for the synthesis of $\mathrm{mS}-11$. Ueda et al., studied the chemical shift perturbations (CSPs) of the PAH1 domain of Sin3 alone or bound to either NRSF of mS-11. The results strongly supported the notion that $\mathrm{mS}-11$ would supplant NRSF-binding to Sin3, thus interfering with NRSF-Sin3 interaction (38).

In the current experiments, we employed mS-11 at high concentrations, which are larger than those tested by Ueda, and should lead to complete displacement of NRSF from the interacting $\mathrm{PAH} 1$ domain of Sin3. Therefore, the current experiments suggest that $\operatorname{Sin} 3$ is not required for the actions of NRSF in Crh-repression in developing hypothalamus. Thus, whereas the results of these experiments are limited lack of definitive evidence that mS-11 displaced NRSF from Sin3 in our system, the high concentrations we employed and the absence of any evidence of doseresponse, together with Ueda et al.'s finding strongly suggest that $\mathrm{mS}-11$ displaced NRSF from Sin3 in the organotypic slice culture. In addition, we employed mS-11 in a concentration that began to exert toxicity on brain tissue. Thus, aiming to improve disruption of Sin3-NRSF interaction using higher $\mathrm{mS}-11$ concentration is not practical.

In conclusion, repression of target genes by NRSF contributes to enduring plasticity in the developing brain. Because NRSF-mediated repression may also underlie disease processes such as the onset of epilepsy, identifying small-molecule antagonists of NRSF is crucial for the development of disease-preventing or modifying interventions. Here we tested if interfering by the interactions of NRSF with its cofactor $\operatorname{Sin} 3$ might provide a therapeutic avenue, using a novel computer-designed small molecule drug. Whereas our data do not support a role of Sin3-NRSF interactions in repression of NRSF target genes in developing hypothalamus, our approach sets the stage for moderate-throughput future drug screening.

\section{Acknowledgements}

We thank Gissell Sanchez for excellent technical help. Research supported by NIH grants NS35439, NS78279. 


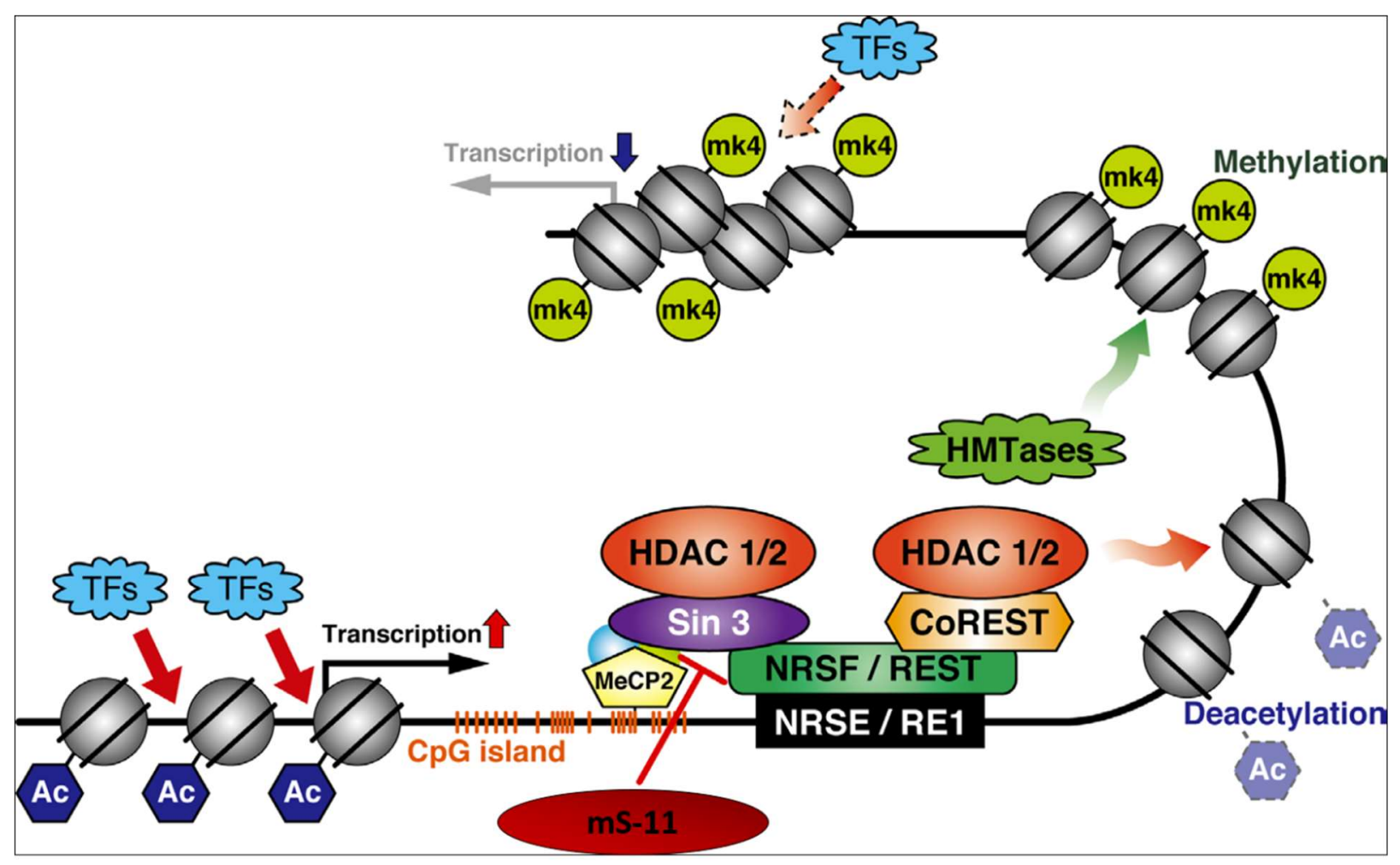

Fig 1. NRSF binds directly to the DNA. It recruits cofactors including $\operatorname{Sin} 3$ to its N-terminus domain and CoREST to its C-terminus domain. These complexes are thought to enable NRSF regulation of gene expression. 

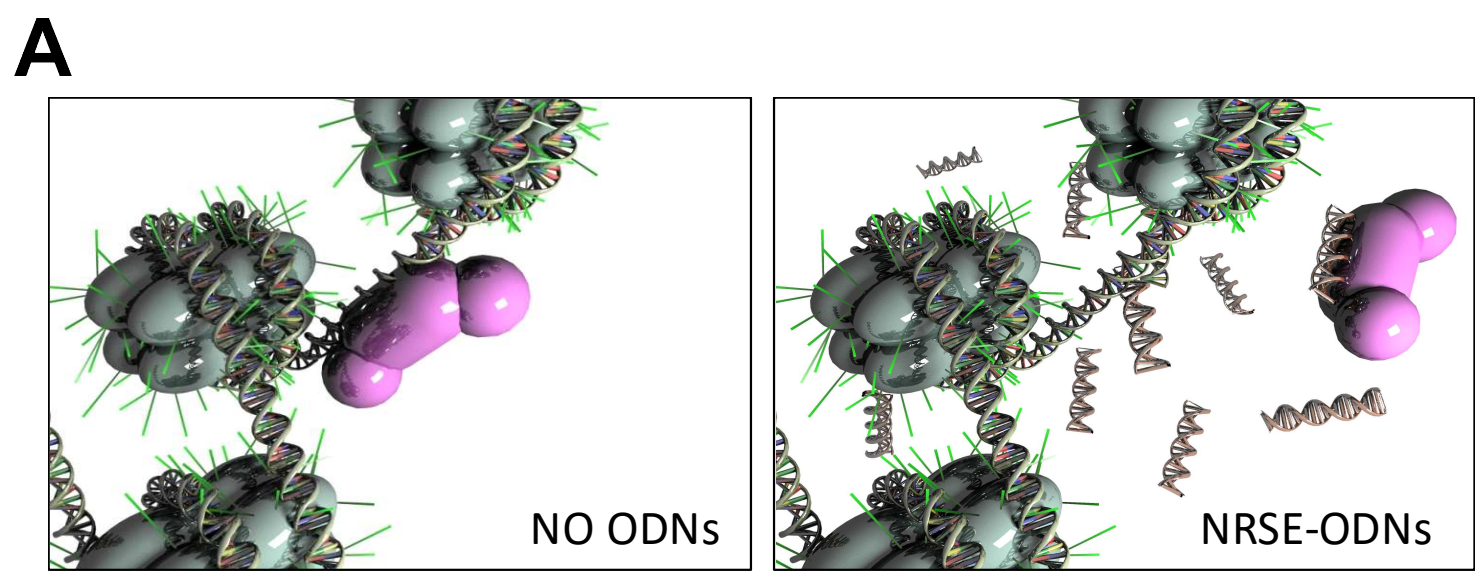

B

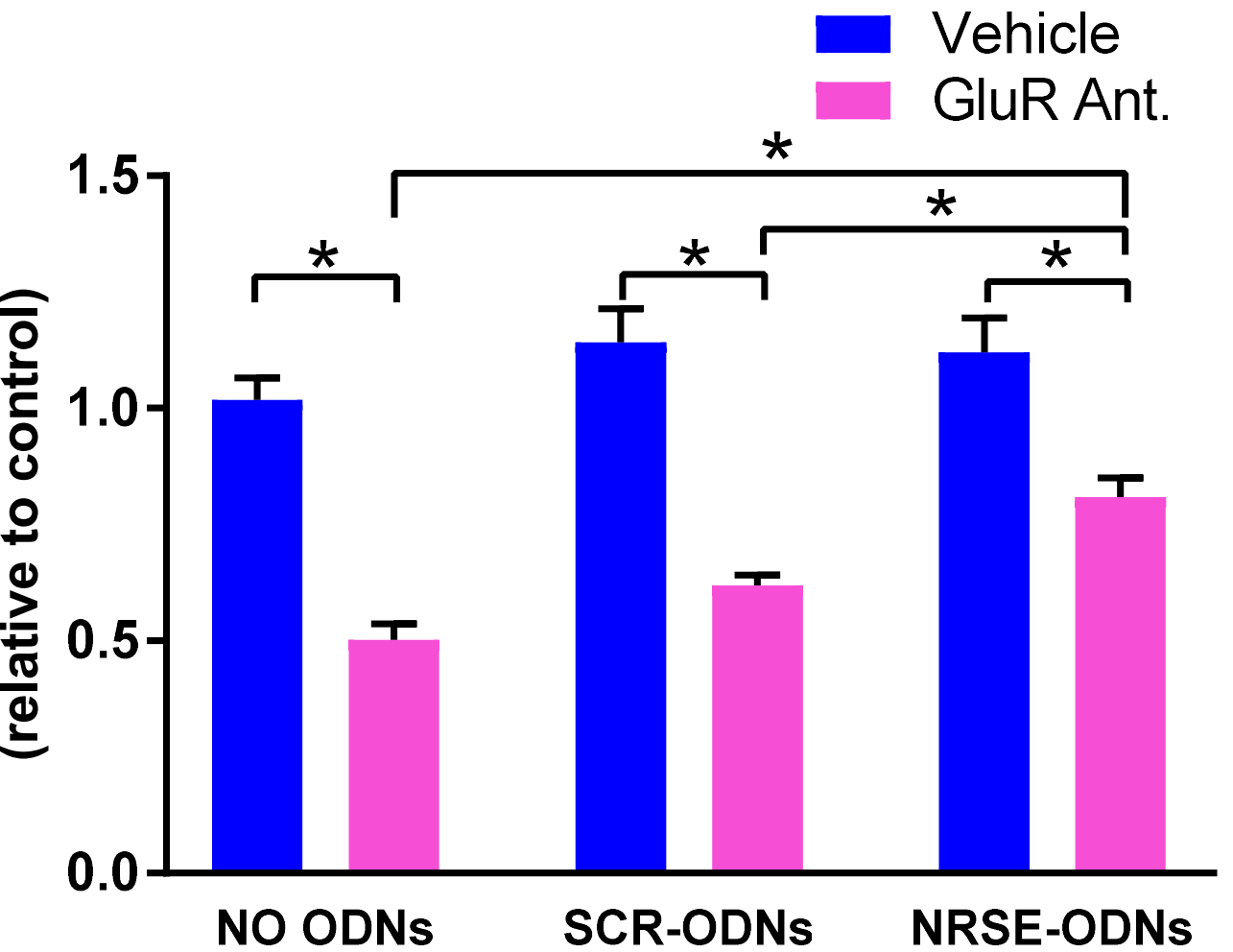

Fig 2. Blocking NRSF binding to the chromatin using NRSE-ODNs prevents the GluR antagonist-induced repression of the Crh gene. (A) NRSE-ODNs act as decoys: they bind NRSF and thus prevent it from binding to RE1/NRSE element on the gene. (B) qPCR for Crh mRNA levels. RNA isolated from hypothalamic cultures after 52 hours and normalized to Gapdh. GluR antagonists (CNQX/MK-801) reduced Crh expression levels and NRSE-ODNs prevented this reduction. This was not evident after application of random (scrambled, SCR) ODNs. Twoway ANOVA; significant interaction, $F_{[2,77]}=7.09$, $p<0.01$; post hoc, ${ }^{*} p<0.05{ }^{*} p<0.09$; $n=11$ 21/group. A) Used under Creative Commons license attributed to Shawn McClelland 


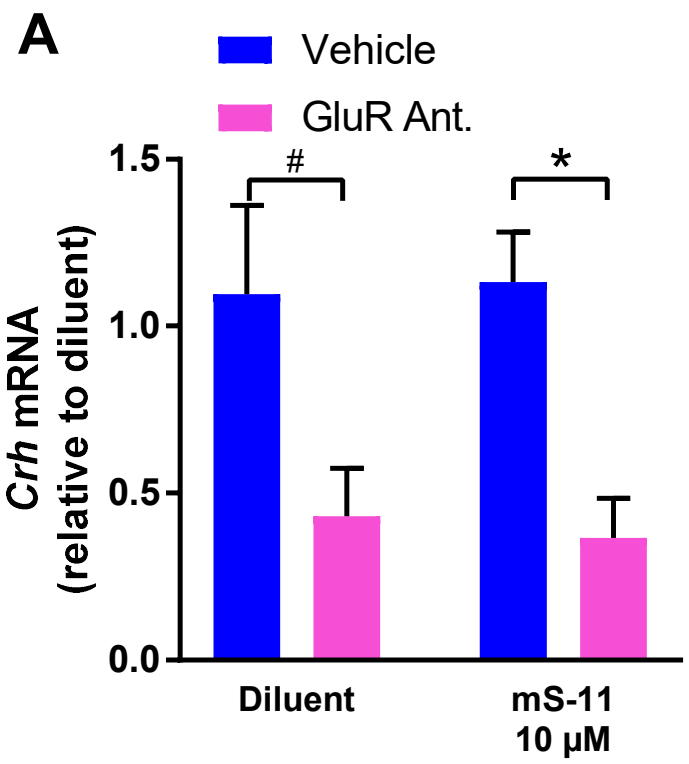

B

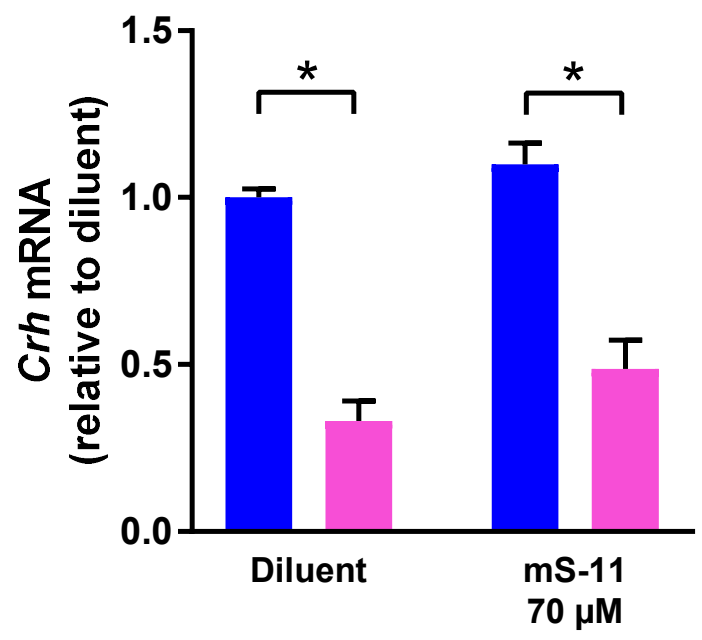

Fig 3. $\mathrm{mS}-11$ did not block GluR antagonist-induced repression of the $\mathbf{C r h}$ gene. Shown are results obtained using qPCR for Crh mRNA levels: RNA was isolated from hypothalamic cultures at 52 hours and was normalized to $\beta$-actin. (A) GluR antagonists (CNQX/MK-801) reduced Crh expression levels and $\mathrm{mS}-11$ had no effect on this reduction at either $10 \mu \mathrm{M}$ (two-way ANOVA; significant main effect of GluR antagonists $F_{[1,12]}=104.5$, $p<0.001 ; n=4 / g r o u p$ ). (B) or $70 \mu \mathrm{M}$ (twoway ANOVA; significant main effect of GluR antagonists, $F_{[1,12]}=15.93, p<0.01 ; n=4 /$ group). 


\section{References}

1. Gao Z, Ure K, Ding P, Nashaat M, Yuan L, Ma J, et al. The master negative regulator REST/NRSF controls adult neurogenesis by restraining the neurogenic program in quiescent stem cells. J Neurosci. 2011 Jun 29;31(26):9772-9786.

2. Ballas N, Mandel G. The many faces of REST oversee epigenetic programming of neuronal genes. Curr Opin Neurobiol. 2005 Oct;15(5):500-506.

3. McClelland S, Brennan GP, Dubé C, Rajpara S, lyer S, Richichi C, et al. The transcription factor NRSF contributes to epileptogenesis by selective repression of a subset of target genes. Elife. 2014 Aug 12;3:e1267.

4. Schoenherr CJ, Anderson DJ. The neuron-restrictive silencer factor (NRSF): a coordinate repressor of multiple neuron-specific genes. Science (80- ). 1995 Mar 3;267(5202):1360-1363.

5. Chen Z-F, Paquette AJ, Anderson DJ. NRSF/REST is required in vivo for repression of multiple neuronal target genes during embryogenesis. Nat Genet. 1998 Oct 1;20(2):136-142.

6. Johnson DS, Mortazavi A, Myers RM, Wold B. Genome-wide mapping of in vivo proteinDNA interactions. Science (80- ). 2007 Jun 8;316(5830):1497-1502.

7. Ballas N, Grunseich C, Lu DD, Speh JC, Mandel G. REST and its corepressors mediate plasticity of neuronal gene chromatin throughout neurogenesis. Cell. 2005 May 20;121(4):645657.

8. Singh-Taylor A, Molet J, Jiang S, Korosi A, Bolton JL, Noam Y, et al. NRSF-dependent epigenetic mechanisms contribute to programming of stress-sensitive neurons by neonatal experience, promoting resilience. Mol Psychiatry. 2017 Jan 10;0:1-10.

9. Lu T, Aron L, Zullo J, Pan Y, Kim H, Chen Y, et al. REST and stress resistance in ageing and Alzheimer's disease. Nature. 2014 Mar 19;507(7493):448-454.

10. Zuccato C, Tartari M, Crotti A, Goffredo D, Valenza M, Conti L, et al. Huntingtin interacts with REST/NRSF to modulate the transcription of NRSE-controlled neuronal genes. Nat Genet. 2003 Sep 27;35(1):76-83.

11. Sun Y-M, Greenway DJ, Johnson R, Street M, Belyaev ND, Deuchars J, et al. Distinct profiles of REST interactions with its target genes at different stages of neuronal development. Mol Biol Cell. 2005 Dec 21;16(12):5630-5638.

12. Goldberg EM, Coulter DA. Mechanisms of epileptogenesis: a convergence on neural circuit dysfunction. Nat Rev Neurosci. 2013 Apr 18;14(5):337-349.

13. Yang YJ, Baltus AE, Mathew RS, Murphy EA, Evrony GD, Gonzalez DM, et al. Microcephaly gene links trithorax and REST/NRSF to control neural stem cell proliferation and differentiation. Cell. 2012 Nov 21;151(5):1097-1112.

14. Thind KK, Ribak CE, Buckmaster PS. Synaptic input to dentate granule cell basal dendrites in a rat model of temporal lobe epilepsy. J Comp Neurol. 2008 Jul 10;509(2):190-202.

15. Amir RE, Van den Veyver IB, Wan M, Tran CQ, Francke $U$, Zoghbi HY. Rett syndrome is caused by mutations in X-linked MECP2, encoding methyl-CpG-binding protein 2. Nat Genet. 1999 Oct 1;23(2):185-188. 
16. Avishai-Eliner S, Brunson KL, Sandman CA, Baram TZ. Stressed-out, or in (utero)? Trends Neurosci. 2002 Oct;25(10):518-524.

17. Lewis DA, Levitt P. Schizophrenia as a disorder of neurodevelopment. Annu Rev Neurosci. 2002 Mar;25(1):409-432.

18. McClelland S, Flynn C, Dubé C, Richichi C, Zha Q, Ghestem A, et al. Neuron-restrictive silencer factor-mediated cyclic nucleotide gated channelopathy in experimental temporal lobe epilepsy. Ann Neurol. 2011 Sep;70(3):454-65.

19. Patterson KP, Baram TZ, Shinnar S. Origins of Temporal Lobe Epilepsy: Febrile Seizures and Febrile Status Epilepticus. Neurotherapeutics. 2014 Apr 7;11(2):242-250.

20. Patterson KP, Barry JM, Curran MM, Singh-Taylor A, Brennan G, Rismanchi N, et al. Enduring Memory Impairments Provoked by Developmental Febrile Seizures Are Mediated by Functional and Structural Effects of Neuronal Restrictive Silencing Factor. J Neurosci. 2017 Apr 5;37(14):3799-3812.

21. Nomura M, Uda-Tochio H, Murai K, Mori N, Nishimura Y. The Neural Repressor NRSF/REST Binds the PAH1 Domain of the Sin3 Corepressor by Using its Distinct Short Hydrophobic Helix. J Mol Biol. 2005 Dec 9;354(4):903-915.

22. Huang Y, Myers SJ, Dingledine R. Transcriptional repression by REST: recruitment of $\operatorname{Sin} 3 \mathrm{~A}$ and histone deacetylase to neuronal genes. Nat Neurosci. 1999 Oct 1;2(10):867-872.

23. Roopra A, Sharling L, Wood IC, Briggs T, Bachfischer U, Paquette AJ, et al. Transcriptional repression by neuron-restrictive silencer factor is mediated via the Sin3-histone deacetylase complex. Mol Cell Biol. 2000 Mar;20(6):2147-2157.

24. Andrés ME, Burger C, Peral-Rubio MJ, Battaglioli E, Anderson ME, Grimes J, et al. CoREST: a functional corepressor required for regulation of neural-specific gene expression. Proc Natl Acad Sci U S A. 1999 Aug 17;96(17):9873-9878.

25. Ballas N, Battaglioli E, Atouf F, Andres ME, Chenoweth J, Anderson ME, et al. Regulation of neuronal traits by a novel transcriptional complex. Neuron. 2001 Aug 16;31(3):353-365.

26. Garriga-Canut M, Schoenike B, Qazi R, Bergendahl K, Daley TJ, Pfender RM, et al. 2Deoxy-D-glucose reduces epilepsy progression by NRSF-CtBP-dependent metabolic regulation of chromatin structure. Nat Neurosci. 2006;9(11):1382-7.

27. Roopra A, Qazi R, Schoenike B, Daley TJ, Morrison JF. Localized domains of G9amediated histone methylation are required for silencing of neuronal genes. Mol Cell. 2004 Jun 18;14(6):727-738.

28. Shi Y, Lan F, Matson C, Mulligan P, Whetstine JR, Cole PA, et al. Histone demethylation mediated by the nuclear amine oxidase homolog LSD1. Cell. 2004 Dec 29;119(7):941-953.

29. Monaghan CE, Nechiporuk T, Jeng S, McWeeney SK, Wang J, Rosenfeld MG, et al. REST corepressors RCOR1 and RCOR2 and the repressor INSM1 regulate the proliferationdifferentiation balance in the developing brain. Proc Natl Acad Sci U S A. 2017 Jan 17;114(3):E406-E415. 
30. Singh-Taylor A, Korosi A, Molet J, Gunn BG, Baram TZ. Synaptic rewiring of stresssensitive neurons by early-life experience: a mechanism for resilience? Neurobiol Stress. 2015 Jan 1;1:109-15.

31. Seth KA, Majzoub JA. Repressor element silencing transcription factor/neuron-restrictive silencing factor (REST/NRSF) can act as an enhancer as well as a repressor of corticotropinreleasing hormone gene transcription. J Biol Chem. 2001 Apr 27;276(17):13917-13923.

32. Mcclelland S, Korosi A, Jessica C, Ivy A, Baram TZ. Emerging Roles od Epigenetic Mechanisms in the Enduring Effects of Neonatal Stress and Experience on Learning and Memory. Neurobiol Learn Mem. 2011;96(1):79-88.

33. Fenoglio KA, Brunson KL, Avishai-Eliner S, Chen Y, Baram TZ. Region-specific onset of handling-induced changes in corticotropin-releasing factor and glucocorticoid receptor expression. Endocrinology. 2004 Jun;145(6):2702-2706.

34. Fenoglio KA, Brunson KL, Avishai-Eliner S, Stone BA, Kapadia BJ, Baram TZ. Enduring, handling-evoked enhancement of hippocampal memory function and glucocorticoid receptor expression involves activation of the corticotropin-releasing factor type 1 receptor. Endocrinology. 2005 Sep;146(9):4090-4096.

35. Fenoglio KA, Chen Y, Baram TZ. Neuroplasticity of the hypothalamic-pituitary-adrenal axis early in life requires recurrent recruitment of stress-regulating brain regions. J Neurosci. 2006 Mar 1;26(9):2434-2442.

36. Avishai-Eliner S, Eghbal-Ahmadi M, Tabachnik E, Brunson KL, Baram TZ. Downregulation of hypothalamic corticotropin-releasing hormone messenger ribonucleic acid (mRNA) precedes early-life experience-induced changes in hippocampal glucocorticoid receptor mRNA. Endocrinology. 2001 Jan;142(1):89-97.

37. Korosi A, Shanabrough M, Mcclelland S, Liu Z-W, Borok E, Gao X-B, et al. Early-Life Experience Reduces Excitation to Stress-Responsive Hypothalamic Neurons and Reprograms the Expression of Corticotropin-Releasing Hormone. J Neurosci. 2010 Jan 13;30(2):703-713.

38. Ueda $\mathrm{H}$, Kurita $\mathrm{J}$ ichi, Neyama H, Hirao $\mathrm{Y}$, Kouji $\mathrm{H}$, Mishina $\mathrm{T}$, et al. A mimetic of the mSin3-binding helix of NRSF/REST ameliorates abnormal pain behavior in chronic pain models. Bioorganic Med Chem Lett. 2017;27(20):4705-4709.

39. Greer PL, Greenberg ME. From synapse to nucleus: calcium-dependent gene transcription in the control of synapse development and function. Neuron. 2008 Sep 25;59(6):846-860.

40. Stroud H, Su SC, Hrvatin S, Greben AW, Renthal W, Boxer LD, et al. Early-Life Gene Expression in Neurons Modulates Lasting Epigenetic States. Cell. 2017 Oct 16;171(5):11511154.e16.

41. Nestler EJ, Peña CJ, Kundakovic M, Mitchell A, Akbarian S. Epigenetic Basis of Mental Illness. Neuroscientist. 2016 Oct 9;22(5):447-463.

42. Delahaye-Duriez A, Srivastava P, Shkura K, Langley SR, Laaniste L, Moreno-Moral A, et al. Rare and common epilepsies converge on a shared gene regulatory network providing opportunities for novel antiepileptic drug discovery. Genome Biol. 2016 Dec 13;17(1):245. 
43. Mitchell AC, Javidfar B, Bicks LK, Neve R, Garbett K, Lander SS, et al. Longitudinal assessment of neuronal 3D genomes in mouse prefrontal cortex. Nat Commun. 2016 Sep $6 ; 7: 12743$.

44. Karsten CA, Baram TZ. How Does a Neuron "know" to Modulate Its Epigenetic Machinery in Response to Early-Life Environment/Experience? Front psychiatry. 2013;4:89.

45. Brennan GP, Dey D, Chen Y, Patterson KP, Magnetta EJ, Hall AM, et al. Dual and Opposing Roles of MicroRNA-124 in Epilepsy Are Mediated through Inflammatory and NRSFDependent Gene Networks. Cell Rep. 2016;14(10):2402-2412.

46. Conforti P, Zuccato C, Gaudenzi G, leraci A, Camnasio S, Buckley NJ, et al. Binding of the repressor complex REST-mSIN3b by small molecules restores neuronal gene transcription in Huntington's disease models. J Neurochem. 2013;127(1):22-35. 